Supporting Information

11 figures, 3 tables

\title{
Chemical characterization and source apportionment of organic aerosols in the coastal city of Chennai, India: Impact of marine air masses on aerosol chemical composition and potential for SOA formation.
}

Snehitha M. Kommula ${ }^{1,2}$, Panda Upasana ${ }^{1,3}$, Amit Sharma ${ }^{1, a}$, Subha S. Raj ${ }^{1,2}$, Ernesto ReyesVillegas $^{4}$, Tianjia Liu ${ }^{5}$, James D. Allan ${ }^{4,6}$, Christi Jose ${ }^{1,2}$, Mira L. Pöhlker ${ }^{7,8}$, Raghunathan Ravikrishna ${ }^{9,2}$, Pengfei Liu ${ }^{10}$, Hang $\mathrm{Su}^{7}$, Scot T. Martin ${ }^{11,5}$ Ulrich Pöschl ${ }^{7}$, Gordon Mcfiggans $^{4}$, Hugh Coe ${ }^{4}$, and Sachin S. Gunthe ${ }^{1,2, *}$

${ }^{1}$ EWRE Division, Dept of Civil Engineering, Indian Institute of Technology Madras, Chennai600036, India

${ }^{2}$ Laboratory for Atmospheric and Climate Sciences, Indian Institute of Technology Madras, Chennai-600036, India

${ }^{3}$ Academy of Scientific and Innovative Research (AcSIR), Department of Environment and Sustainability, CSIR - Institute of Minerals and Materials Technology, Bhubaneswar-751013, India

${ }^{4}$ Department of Earth and Environmental Sciences, School of Natural Sciences, University of Manchester, Manchester, M13 9PL, UK

${ }^{5}$ Department of Earth and Planetary Sciences, Harvard University, Cambridge, MA 02138, USA

${ }^{6}$ National Centre for Atmospheric Science, University of Manchester, Manchester, M13 9PL, UK

${ }^{7}$ Multiphase Chemistry and Biogeochemistry Department, Max Planck Institute for Chemistry, 55020 Mainz, Germany

${ }^{8}$ Experimental Aerosol and Cloud Microphysics Department, Leibniz Institute for Tropospheric Research, 04318 Leipzig, Germany

${ }^{9}$ Department of Chemical Engineering, Indian Institute of Technology Madras, Chennai600036, India

${ }^{10}$ School of Earth and Atmospheric Sciences, Georgia Institute of Technology, Atlanta, GA 30332, USA

${ }^{11}$ John A. Paulson School of Engineering and Applied Sciences, Harvard University, Cambridge, MA 02138, USA

a now at: Department of Civil and Infrastructure Engineering, Indian Institute of Technology Jodhpur, Jodhpur - 342001, India

${ }^{*}$ Correspondence to: Sachin S. Gunthe (s.gunthe@iitm.ac.in) 
Table S1. A summary of submicron NR-PM 1 species measured by ACSM, $\mathrm{PM}_{2.5}$ taken from US embassy, BC measured by AE33, OA factors and ALWC for the entire campaign and the periods divided. Values show the mass concentration $\left(\mu \mathrm{g} \mathrm{m}^{-3} \pm\right.$ standard deviation). The mean elemental ratios (O:C and $\mathrm{H}: \mathrm{C})$, temperature, relative humidity and wind speed are also shown.

\begin{tabular}{|c|c|c|c|}
\hline \multicolumn{4}{|c|}{ Chennai } \\
\hline $\begin{array}{l}\text { Aerosol species in }(\mu \mathrm{g} \\
\left.\mathrm{m}^{-3}\right) \text { and } \\
\text { Meteorological } \\
\text { parameters }\end{array}$ & $\begin{array}{l}\text { Mean value for } \\
\text { Entire campaign }\end{array}$ & $\begin{array}{l}\text { Values averaged for } \\
\text { Rest of the campaign }\end{array}$ & $\begin{array}{l}\text { Values averaged over } \\
\text { Clean marine period }\end{array}$ \\
\hline Org & $14.5 \pm 17.2$ & $15.6 \pm 17.9$ & $4.9 \pm 1.7$ \\
\hline $\mathrm{SO}_{4}{ }^{2-}$ & $10.2 \pm 7.4$ & $11.0 \pm 7.3$ & $1.9 \pm 0.6$ \\
\hline $\mathrm{NH}_{4}^{+}$ & $3.6 \pm 2.7$ & $3.9 \pm 2.7$ & $0.8 \pm 0.4$ \\
\hline $\mathrm{NO}_{3}^{-}$ & $1.4 \pm 2.0$ & $1.5 \pm 2.1$ & $0.2 \pm 0.1$ \\
\hline Chl & $0.8 \pm 2.5$ & $0.9 \pm 2.6$ & $0.04 \pm 0.04$ \\
\hline $\mathrm{NR}_{-} \mathrm{PM}_{1}$ & $30.6 \pm 28.6$ & $33.3 \pm 29.1$ & $7.9 \pm 2.5$ \\
\hline $\mathrm{PM}_{2.5}$ & $63.3 \pm 41.9$ & $69.4 \pm 39.3$ & $10.2 \pm 6.3$ \\
\hline $\mathrm{BC}$ & $9.4 \pm 9.6$ & $10.1 \pm 9.9$ & $3.2 \pm 1.0$ \\
\hline POA & $6.7 \pm 11.8$ & $7.5 \pm 4.9$ & $0.9 \pm 0.6$ \\
\hline SOA & $7.2 \pm 4.9$ & $7.4 \pm 12.3$ & $3.9 \pm 1.2$ \\
\hline ALWC & $17.6 \pm 17.3$ & $19.2 \pm 17.8$ & $5.9 \pm 3.0$ \\
\hline $\mathrm{O}: \mathrm{C}$ & 0.6 & 0.6 & 0.8 \\
\hline $\mathrm{H}: \mathrm{C}$ & 1.5 & 1.5 & 1.4 \\
\hline Temperature $\left({ }^{\circ} \mathrm{C}\right)$ & 24.8 & 24.6 & 26.2 \\
\hline Relative humidity (\%) & 69.5 & 69.0 & 73.3 \\
\hline Wind speed $(\mathrm{m} / \mathrm{s})$ & 1.3 & 1.2 & 1.4 \\
\hline
\end{tabular}




\section{ACSM tuning and calibration:}

The instrument was tuned and calibrated at the beginning of campaign following the protocols mentioned in ( $\mathrm{Ng}$ et al., 2011a). The ion source, vaporizer and quadrupole resolution were tuned and adjusted. Multiplier voltage was adjusted and $\mathrm{m} / \mathrm{z}$ calibration was conducted. Lens alignment and ionization efficiency calibration was performed with $300 \mathrm{~nm} \mathrm{NH}_{4} \mathrm{NO}_{3}$ and $\left(\mathrm{NH}_{4}\right)_{2} \mathrm{SO}_{4}$ aerosols generated in the laboratory, for the response factor (RF) of $\mathrm{NO}_{3}$ and relative ionization efficiencies $\left(\mathrm{RIE}_{\mathrm{s}}\right)$ of $\mathrm{NH}_{4}$ and $\mathrm{SO}_{4}$. The $\mathrm{RF}$ and $\mathrm{RIE}$ obtained from the calibration were applied to the measured dataset.

Table S2. Table for the obtained calibration values used for the measured campaign.

\begin{tabular}{c|c|c}
\hline Species & RIE & RF \\
\hline Organics & 1.4 & \\
Sulfate & 1.08 & \\
Ammonium & 4.96 & \\
Nitrate & 1.1 & $7.65 \mathrm{E}-11$ \\
Chloride & 1.3 & \\
\hline
\end{tabular}

\section{Evaluation of PMF solution:}

The sources of organic aerosols were identified by unconstrained PMF runs (Section 2). The 15 min averaged organic mass spectra matrix obtained from ACSM software was input to the SoFi and after examining a range of solutions from 2 to 9 factors, a four-factor solution accurately represented the rest of the campaign data with $Q / Q_{\exp }$ value of 0.66 . Factor 1 showed a spectral pattern similar to that of standard hydrocarbon-like OA, that was characterized by the presence of $\mathrm{C}_{\mathrm{n}} \mathrm{H}_{2 \mathrm{n}+1}{ }^{+}, \mathrm{C}_{\mathrm{n}} \mathrm{H}_{2 \mathrm{n}-1}{ }^{+}$ion series. The mass spectrum of factor 2 showed similar profile to that of biomass burning OA with characteristic peaks at standard wood burning tracer $\mathrm{m} / \mathrm{z} 60,73$. Factor 3 and 4 were identified by the abundant signal peaks at $\mathrm{m} / \mathrm{z} 43,44$ which resembled the secondary organic aerosols, less oxidized oxygenated OA (LO-OOA) and more oxidized oxygenated OA (MO-OOA), respectively.

Meanwhile, when solution with five OA sources is considered for rest of the campaign, HOA is observed to split in to two factors with similar timeseries and profiles, one of which is 
observed to have slightly greater $\mathrm{m} / \mathrm{z} 55 / 57$ ratio, indicating the cooking emissions (Allan et al., 2010; Crippa et al., 2013; Mohr et al., 2012). Typical cooking are distinguished based on their unique diurnal trend with emission peaks at lunch and dinner time, as, chemical tracers for cooking emissions has not yet been clearly established, despite several laboratory studies (Mohr et al., 2012; Reyes-Villegas et al., 2018). However, the new factor has shown similar time series and diurnal trend as that of HOA without peaking at lunch and dinner time, therefore labelled as HOA-2. The timeseries and factor profiles for five factor solution is shown in Fig. $\mathrm{S} 3 \mathrm{a}, \mathrm{b}$. Note that the timeseries of factor 1 (HOA-1) and factor 2 (HOA-2) were almost similar with a correlation $\left(\mathrm{r}^{2}\right)$ of 0.87 and their diurnal variation is same (Fig. S3c), with a large peak in the morning followed by a small peak at the night, indicating the splitting or repetition of already existed factors. A small contribution of COA could be possible, while cannot be accurately separated by the PMF analysis due to the low signal-to-noises. As a result, a fourfactor solution was chosen for rest of the campaign in this study.

Table S3. Elemental ratios and correlation of OA factor profiles with reference/standard mass spectra (Ng et al., 2011b) for the periods classified.

\begin{tabular}{lccc}
\hline OA factors & $\begin{array}{c}\text { Correlation with reference } \\
\text { mass spectra }\left(\mathbf{R}_{\mathbf{u c}}\right)\end{array}$ & O:C & H:C \\
\hline Rest of the campaign & 0.88 & 0.08 & 1.54 \\
HOA & 0.73 & 0.13 & 1.35 \\
BBOA & 0.92 & 0.35 & 1.76 \\
LO-OOA & 0.90 & 0.98 & 1.27 \\
MO-OOA & & & \\
Clean marine period & 0.89 & 0.08 & 1.59 \\
HOA & 0.96 & 0.92 & 1.41 \\
MO-OOA & & \\
\hline
\end{tabular}


(a)

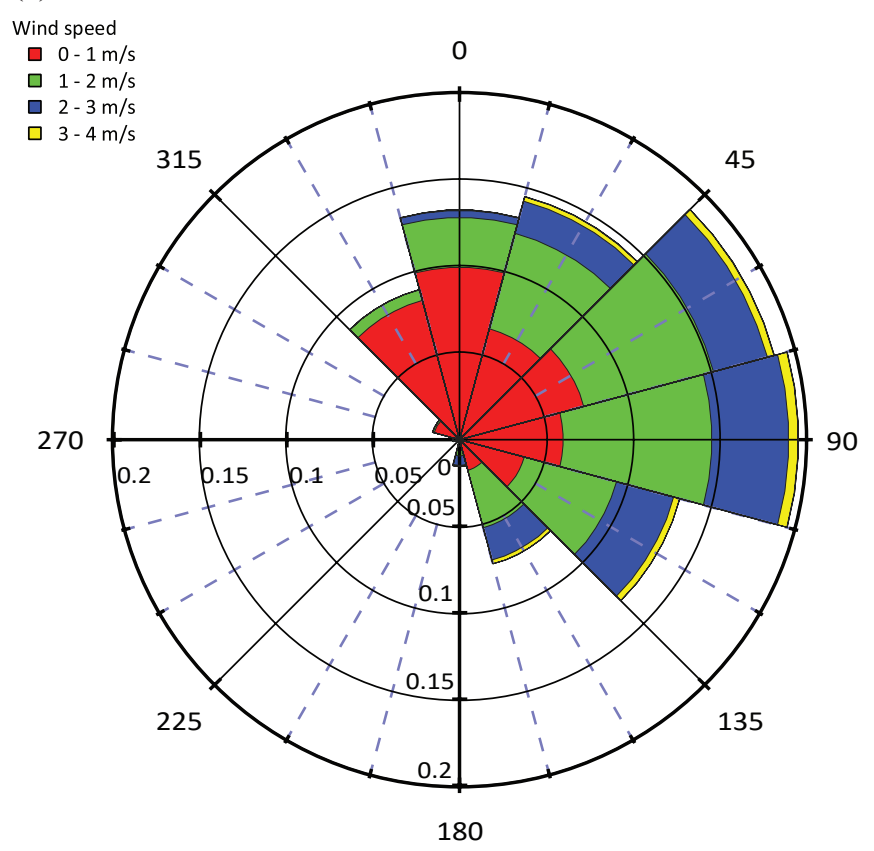

(b)

\section{Clean marine period}

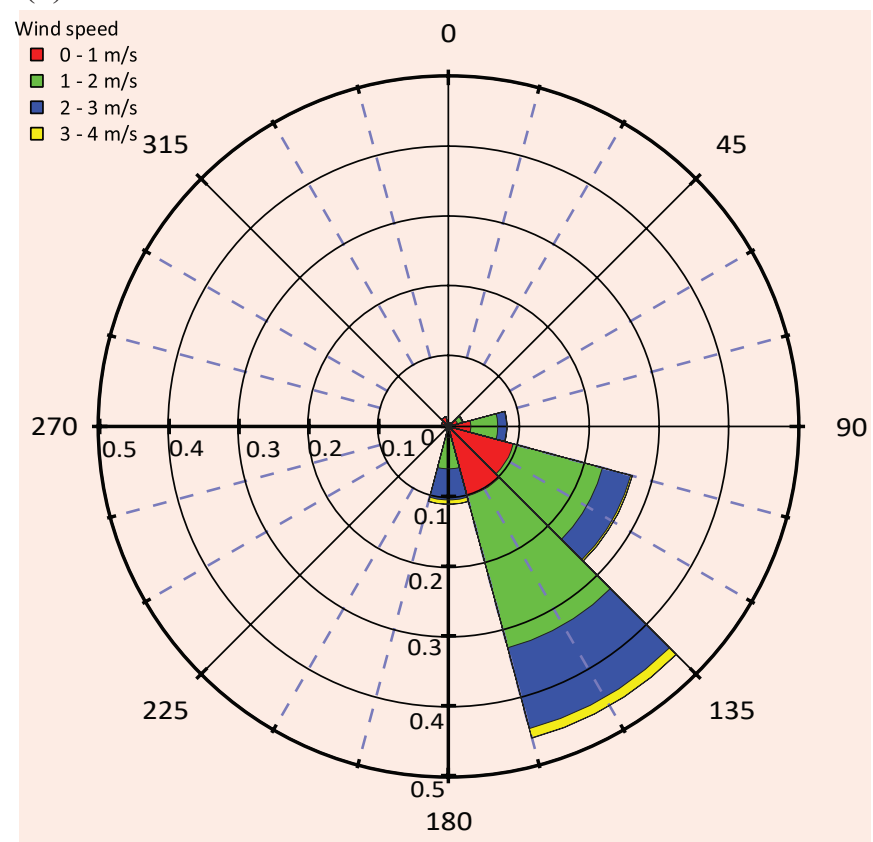

Figure S1. Wind rose of NR-PM1 species, measured in Chennai, for the divided periods (rest of the campaign (left) and clean marine period (right). (a) wind rose diagram for rest of the campaign shows that out of $\sim 35 \%$ of the frequency of occurrence of winds with a speed of $0-1 \mathrm{~m} / \mathrm{s}, \sim 18 \%$ were associated with northwest and north direction (continent); In contrast (b) wind rose diagram of clean marine period shows no winds associated with northwest direction but $\sim 50 \%$ of the frequency of occurrence of high-speed winds (1-4 m/s) were associated with south east direction. 

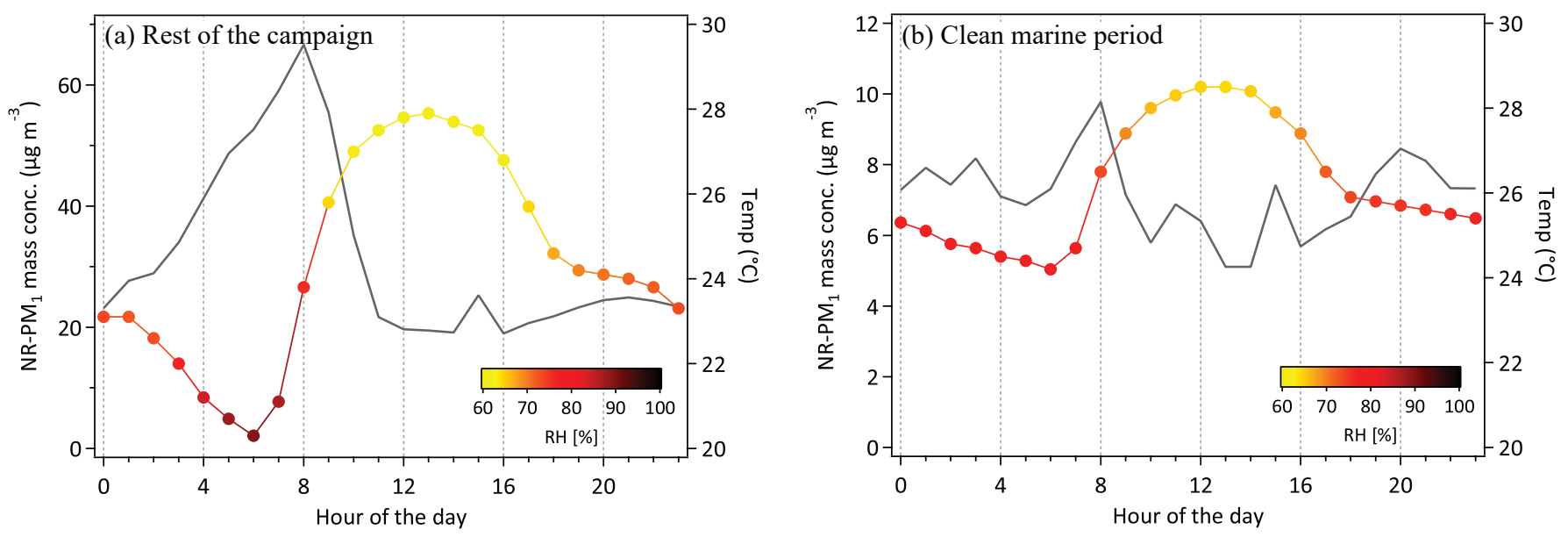

Figure S2. The diurnal variation of total NR-PM1 and temperature color coded by RH during (a) Rest of the campaign and (b) Clean marine period. 
(a)
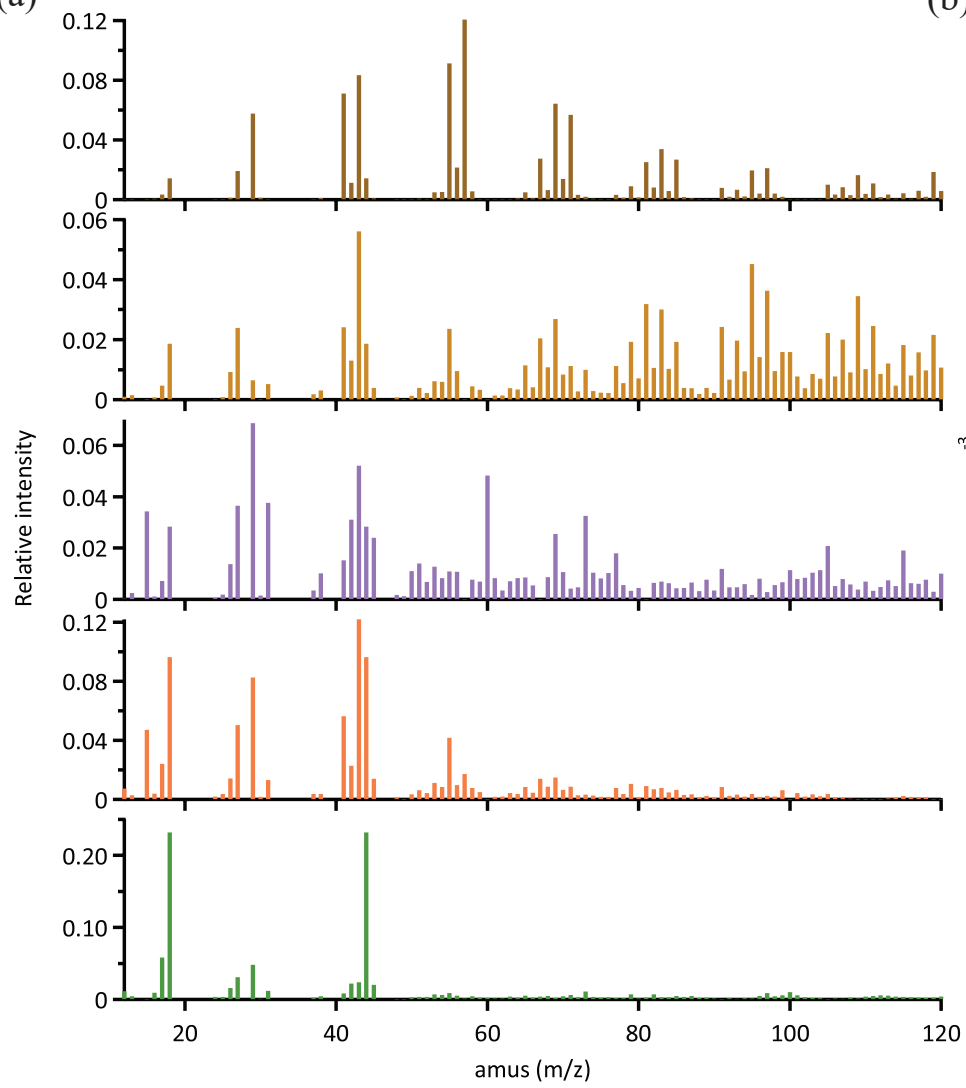

(b)
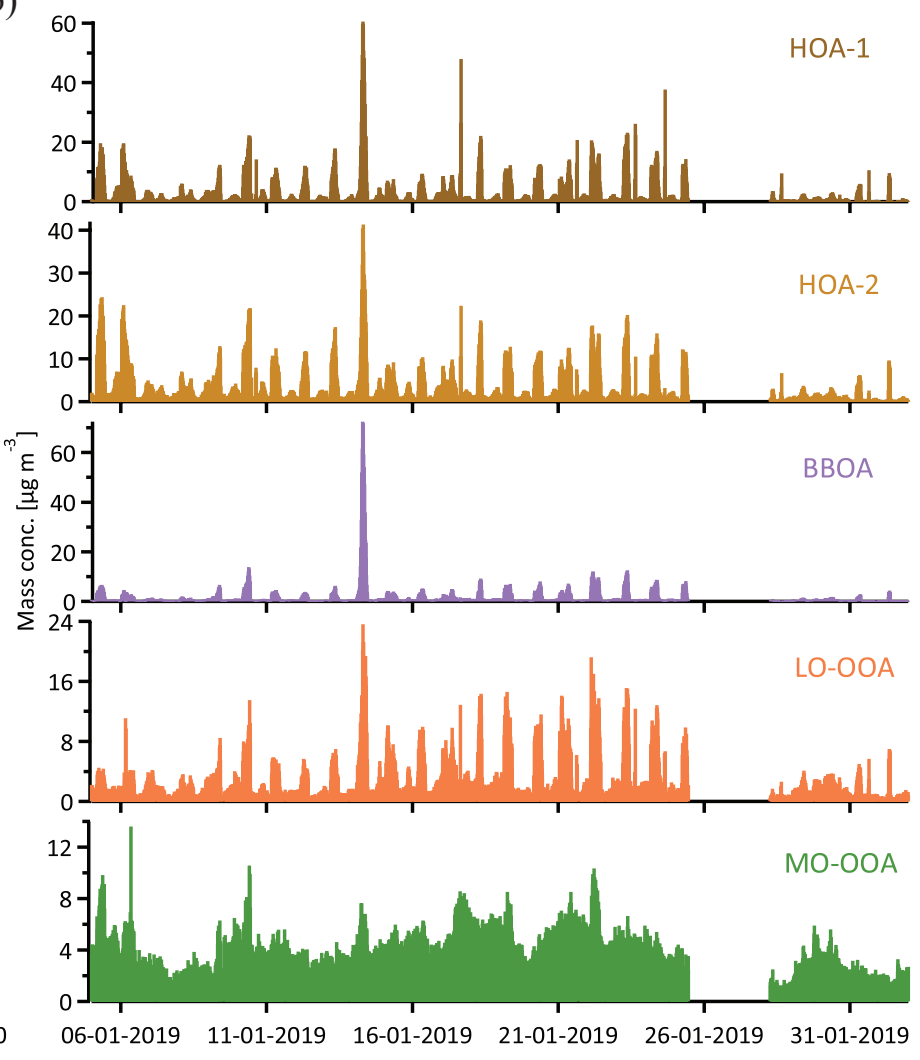

Time series

Figure S3. (a) Mass spectra profiles and (b) timeseries of OA factors from 5-factor PMF solution for rest of the campaign period.

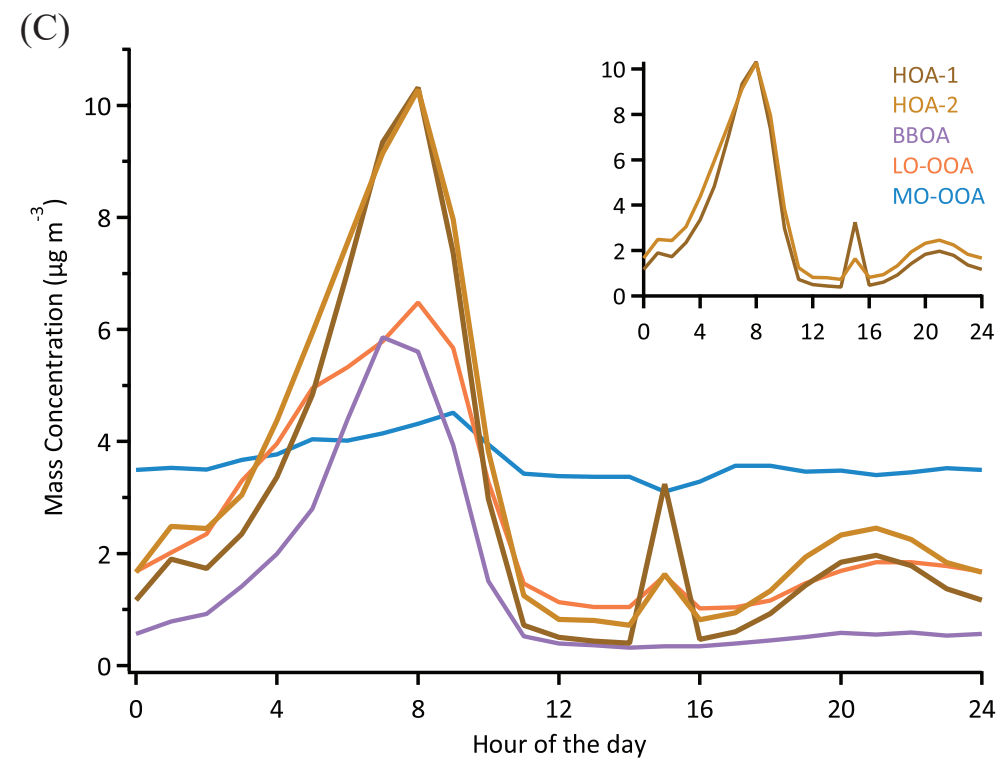

Figure S3. (c) Diurnal variation of the OA factors for rest of the campaign period. The inset shows the diurnal variation of factor 1 and 2, where similiar pattern was observed for both factors indicating the repetition/splitting of already existing factor. 

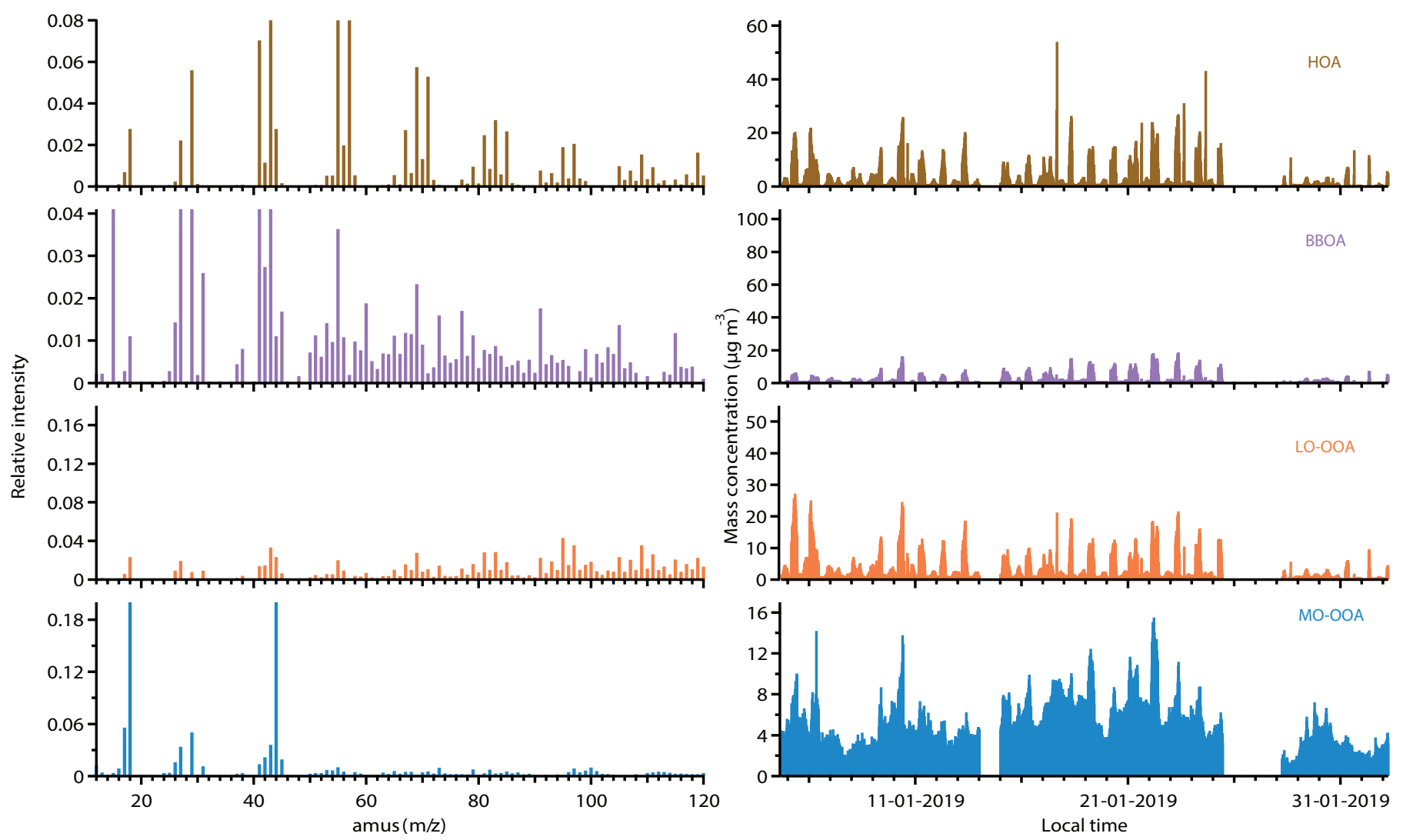

Figure S4. Four factor PMF solution (mass spectra profiles and time series) for the "rest of the campaign" period after excluding Bhogi festival. 

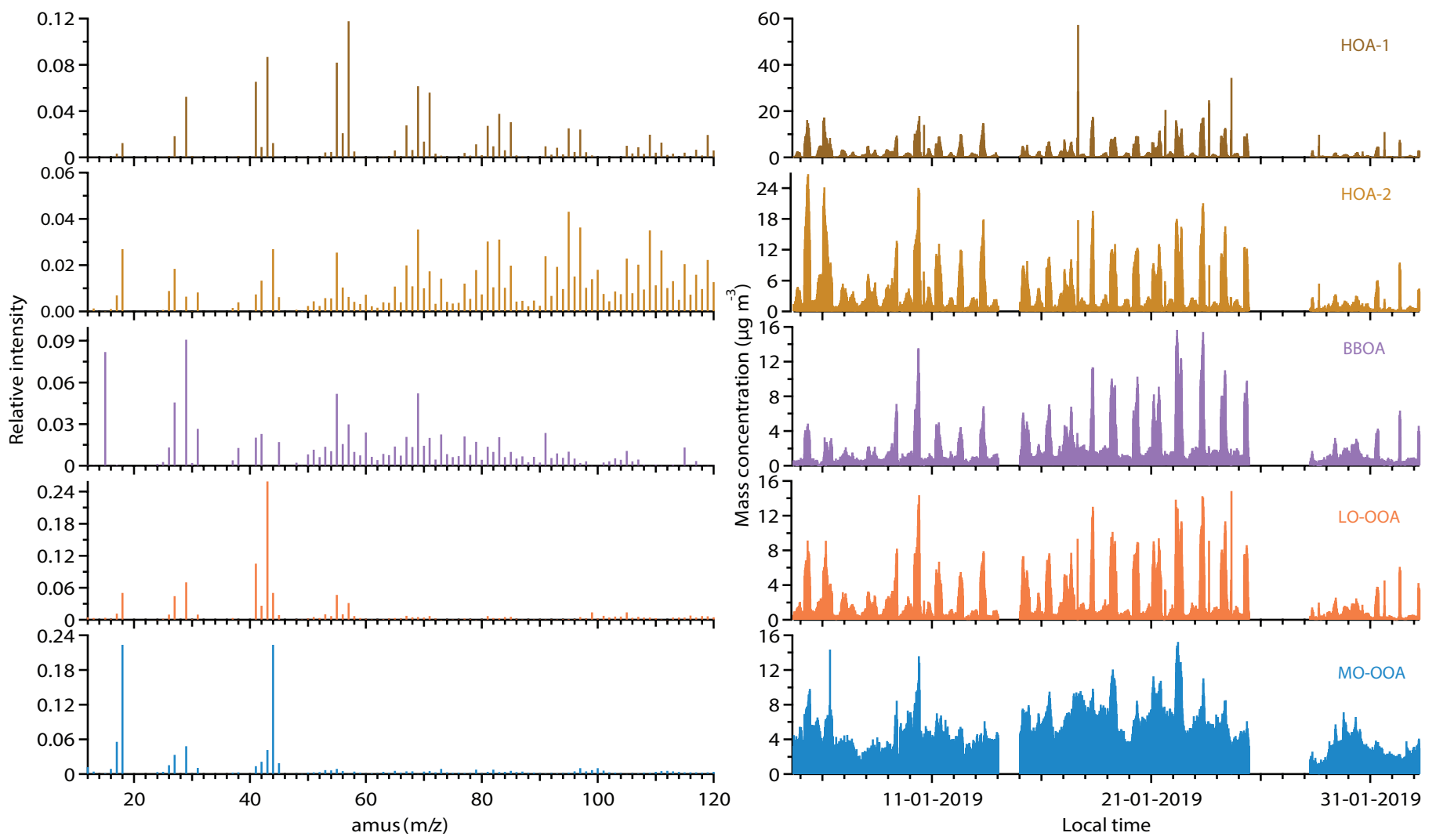

Figure S5. Five-factor PMF solution for the "rest of the campaign" period after excluding Bhogi festival. Here, the primary combustion factors were observed to split and apart from that no minor or other local sources were identified after excluding Bhogi day. 


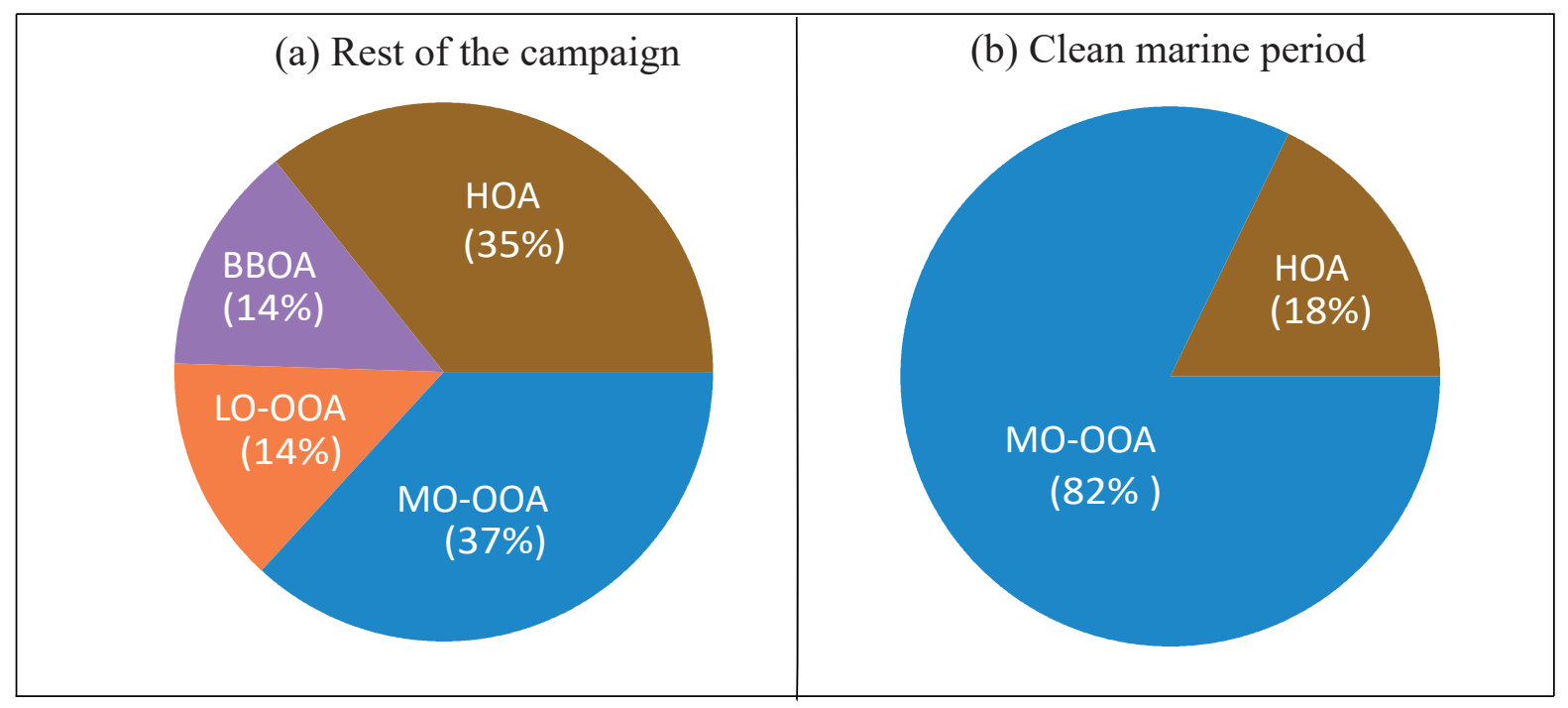

Figure S6. The relative contribution of OA factors identified for (a) Rest of the campaign and (b) Clean marine period, using PMF. 

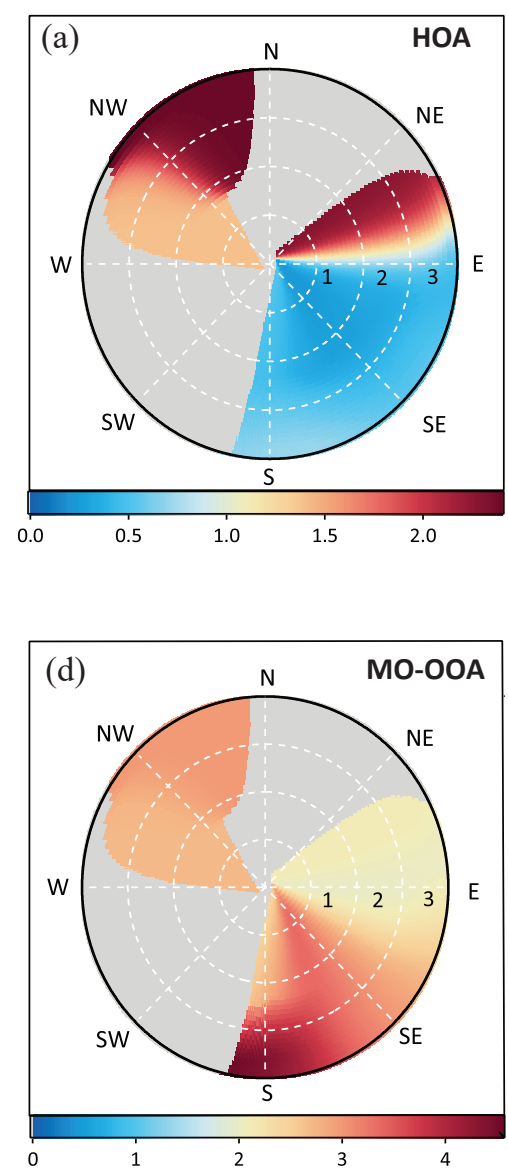
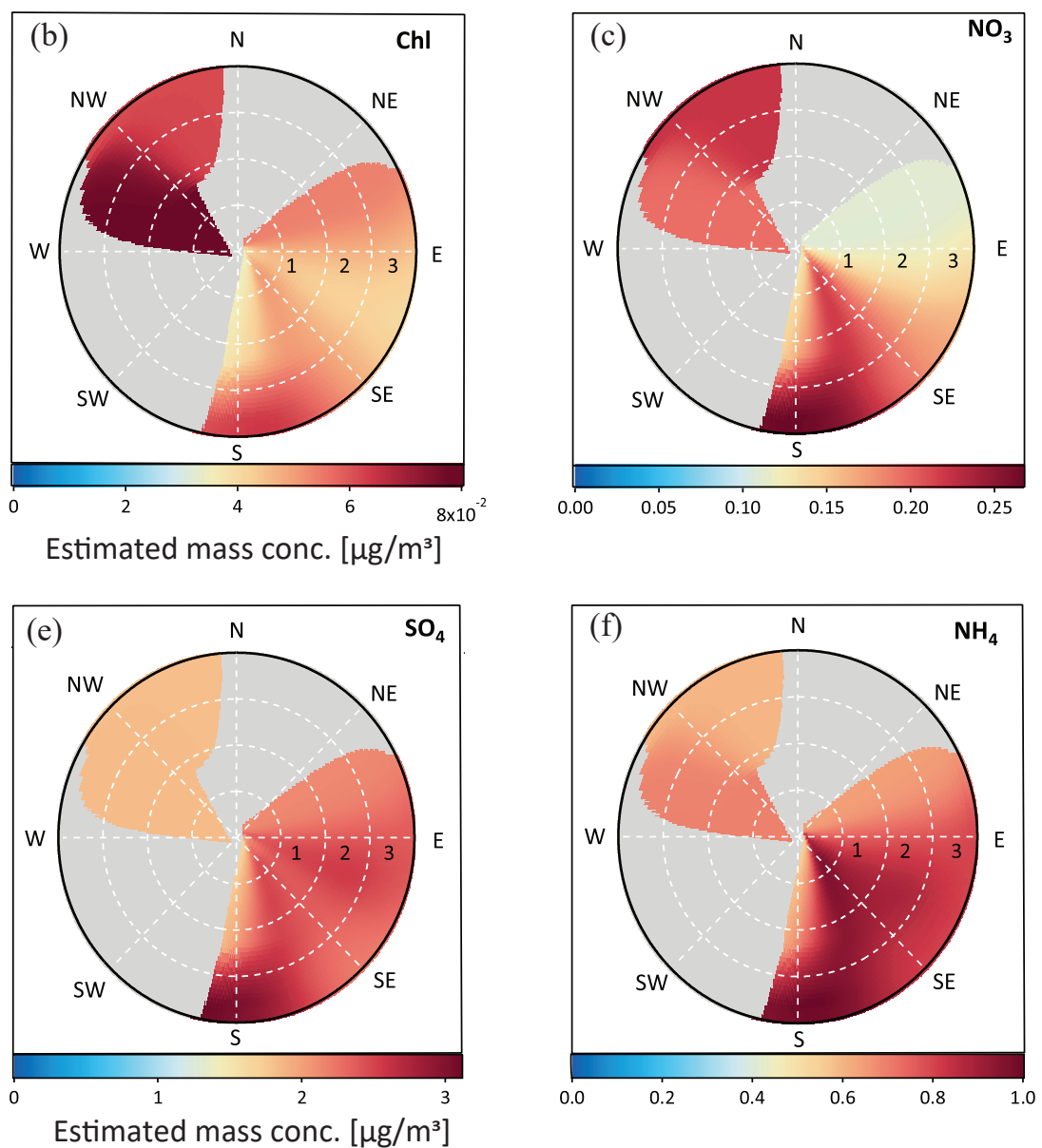

Figure S7. NWR estimates of the organic sources apportioned using PMF model and non-refractory submicron chemical species measured by the ACSM for clean marine period. (a) HOA; (b) Chl; (c) $\mathrm{NO}_{3}$; (d) MO-OOA; (e) $\mathrm{SO}_{4}$; and (f) $\mathrm{NH}_{4}$. The radial values represent wind speed in $\mathrm{m} / \mathrm{s}$ and the colour bar scale corresponds to estmated mass concentration of species in $\mu \mathrm{g} / \mathrm{m}^{3}$. 
(a) Rest of the campaign

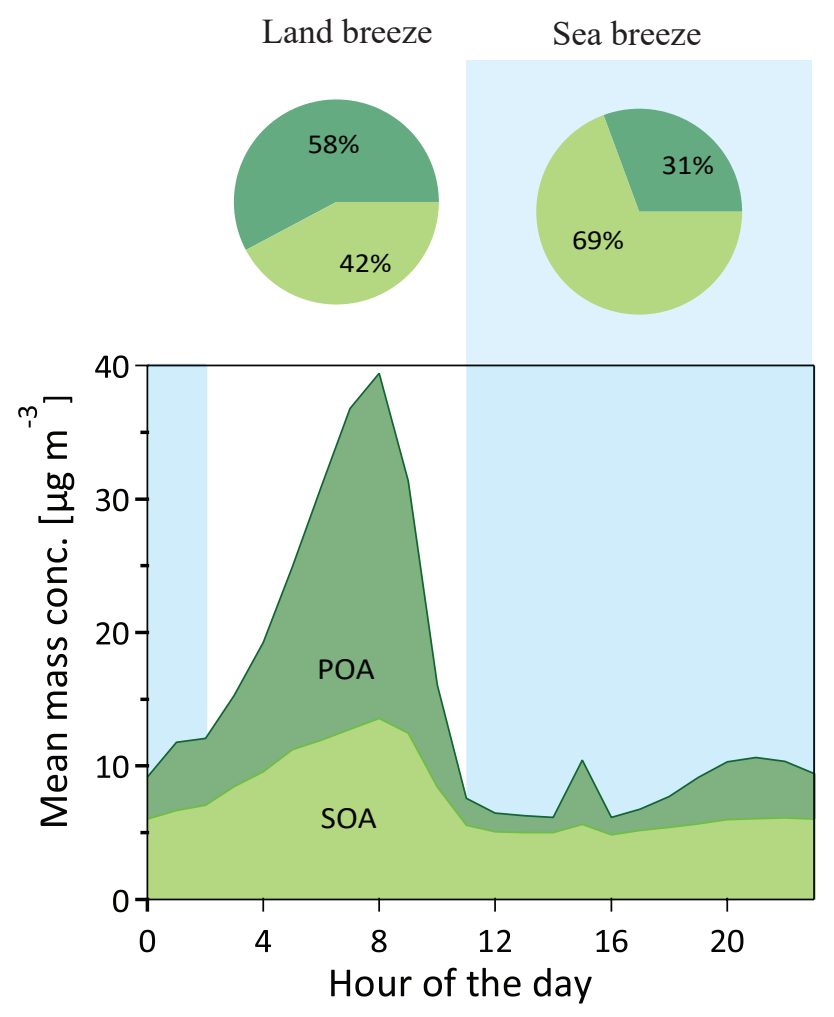

(b) Clean marine period

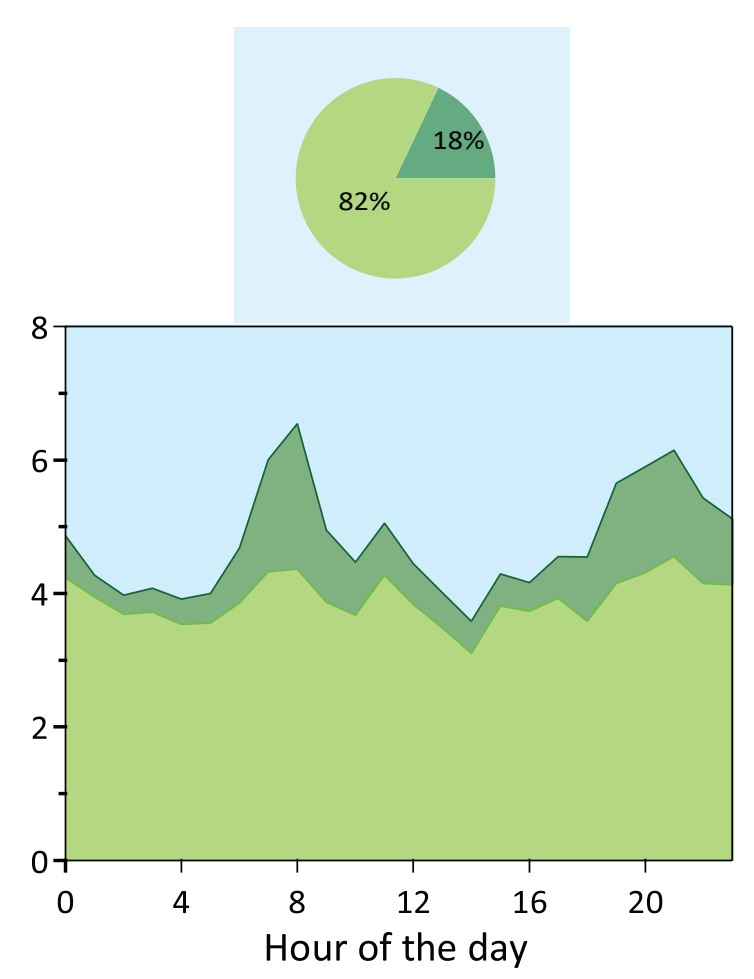

Figure S8. The diurnal variation of absolute mass concentration of primary and secondary OA factors stacked on top of each other during (a) Rest of the campaign and (b) Clean marine period. The time of the day with marine winds are shaded in blue colour. The relative contributions of POA and SOA during land and sea breeze are shown in the pie charts. 
(a) Entire campaign

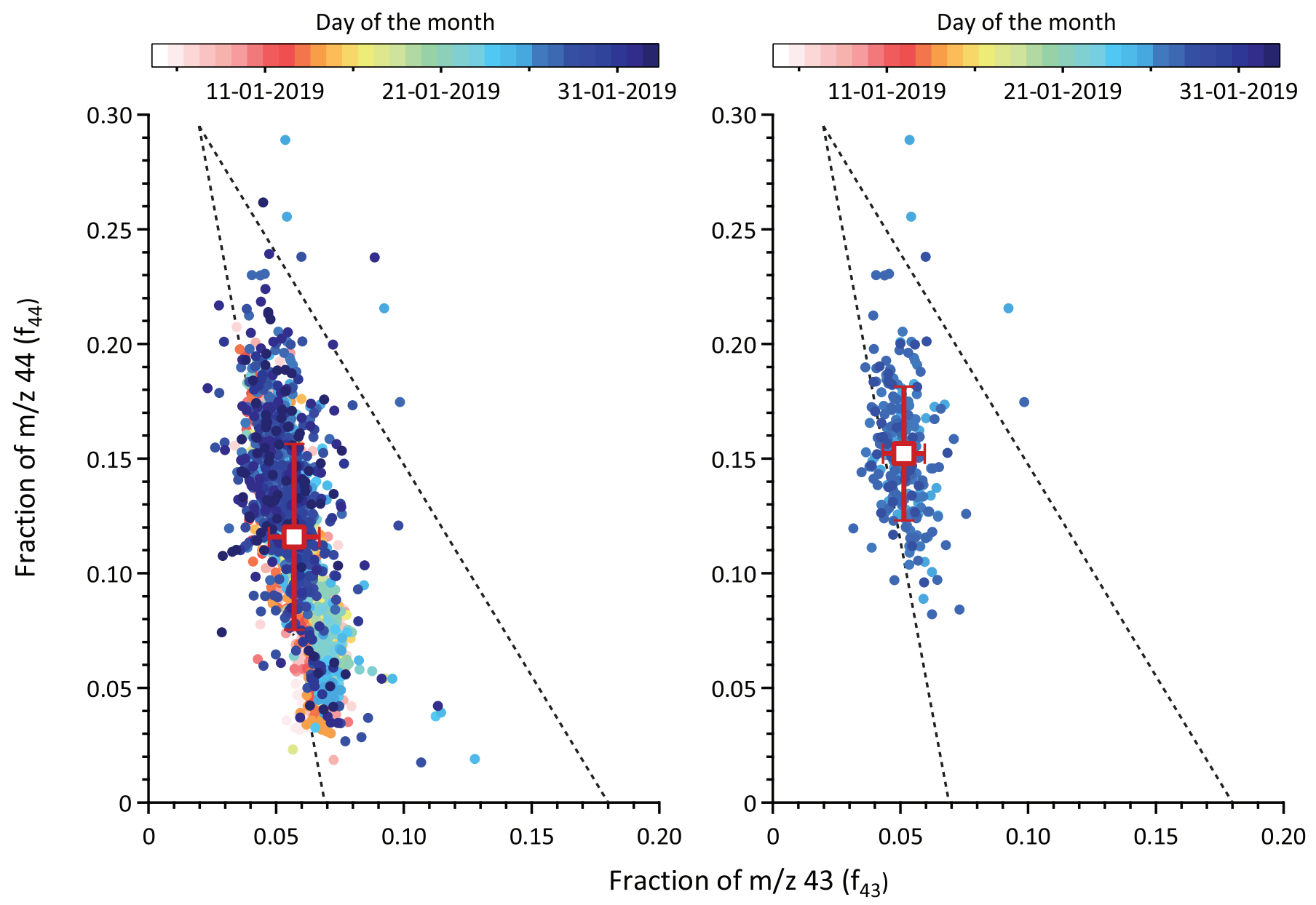

Figure S9. Fraction of signal at $\mathrm{m} / \mathrm{z} 44$ plotted against fraction of signal at $\mathrm{m} / \mathrm{z} 43$ for (a) Entire campaign period and (b) Clean marine period. The square point in each panel represents the mean values for selected period and error bar represents the standard deviation. Panel (a) shows that the ambient aerosols in Chennai during measurement period are well mixture of both primary (fresh) and secondary particles. The higher $f_{44}$ values reveals the occurrence of rapid oxidation processes in coastal city, which is more evident during (b) clean period with marine influx. 

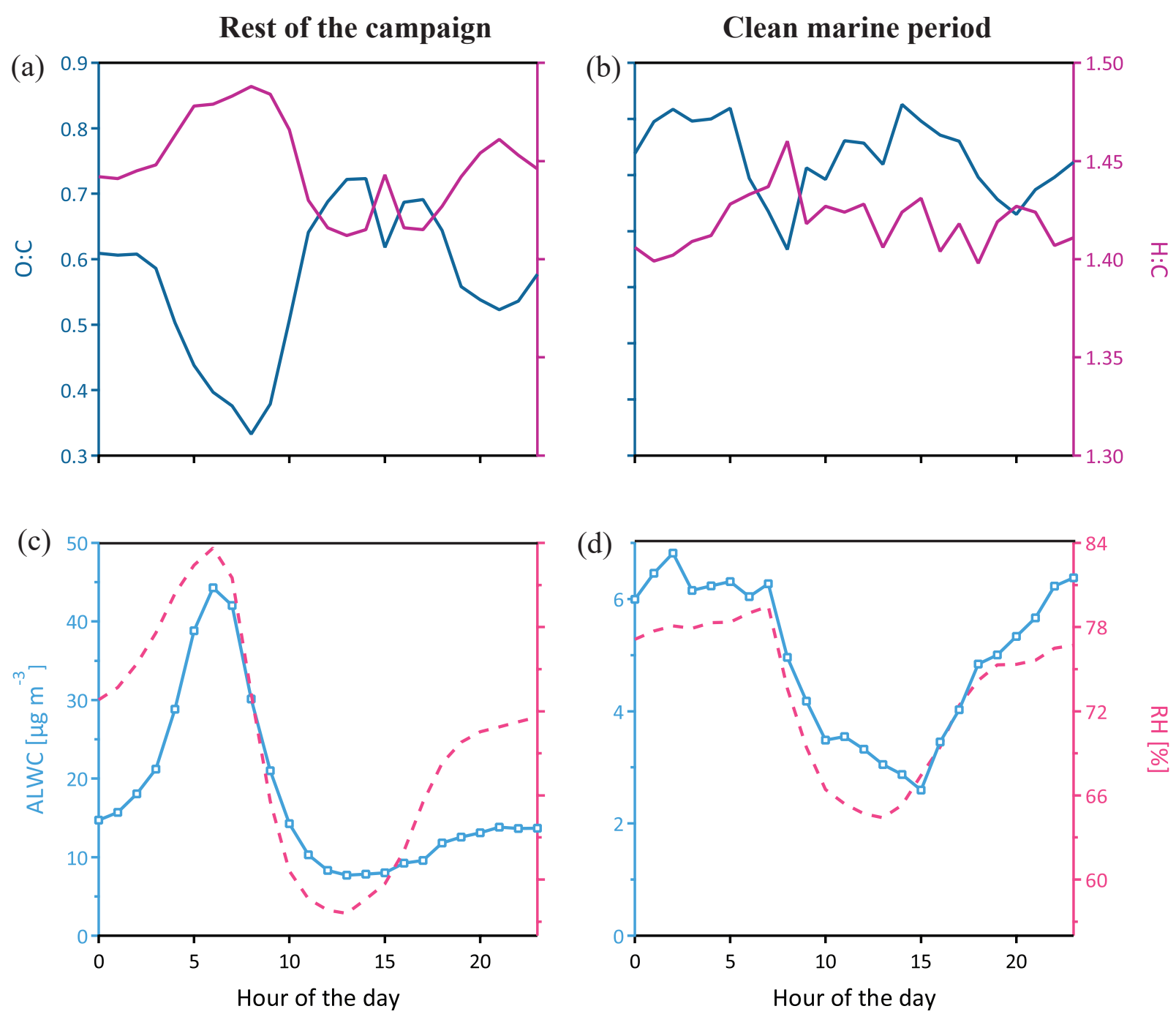

Figure S10. Diurnal variation of elemental ratios O:C and H:C for (a) rest of the campaign and (b) clean marine period; The diurnal cycle of Aerosol liquid water content (ALWC) predicting using ISORROPIA and ambient relative humidity $(\mathrm{RH})$ averaged over (c) rest of the campaign and (d) clean marine period. 

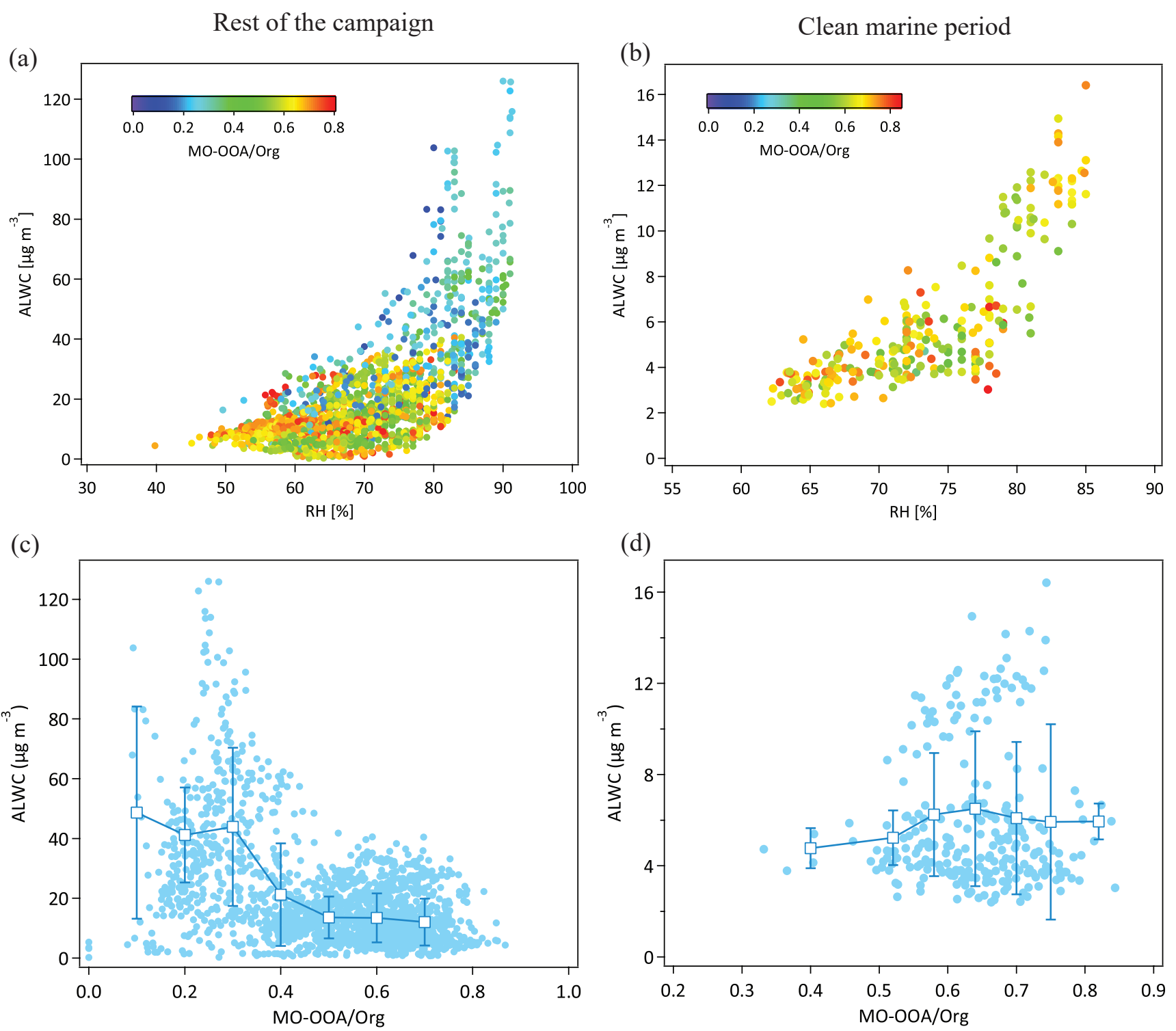

Figure S11. Aerosol liquid water content (ALWC) as a function of ambient relative humidity colored by mass fraction of MO-OOA for (a) rest of the campaign and (b) clean marine period; ALWC as a function of fraction of MO-OOA for (c) rest of the campaign and (d) clean marine period. ALWC was decreasing with increase in fraction of MO-OOA during rest of the campaign, while during clean marine period it has shown relatively increasing trend with increase in MO-OOA fraction. 


\section{REFERENCES}

1. Allan, D., Williams, P. I., Morgan, W. T., Martin, C. L., Flynn, M. J., Lee, J., Nemitz, E., Phillips, G. J., Gallagher, M. W. and Coe, H.: Contributions from transport, solid fuel burning and cooking to primary organic aerosols in two UK cities, Atmos. Chem. Phys., 10(2), 647-668, doi:10.5194/acp-10-647-2010, 2010.

2. Crippa, M., El Haddad, I., Slowik, J. G., Decarlo, P. F., Mohr, C., Heringa, M. F., Chirico, R., Marchand, N., Sciare, J., Baltensperger, U. and Prévôt, A. S. H.: Identification of marine and continental aerosol sources in Paris using high resolution aerosol mass spectrometry, J. Geophys. Res. Atmos., 118(4), 1950-1963, doi:10.1002/jgrd.50151, 2013.

3. Mohr, C., DeCarlo, P. F., Heringa, M. F., Chirico, R., Slowik, J. G., Richter, R., Reche, C., Alastuey, A., Querol, X., Seco, R., Peñuelas, J., Jiḿenez, J. L., Crippa, M., Zimmermann, R., Baltensperger, U. and Prévot, A. S. H.: Identification and quantification of organic aerosol from cooking and other sources in Barcelona using aerosol mass spectrometer data, Atmos. Chem. Phys., 12(4), 1649-1665, doi:10.5194/acp-12-1649-2012, 2012.

4. Ng, N. L., Herndon, S. C., Trimborn, A., Canagaratna, M. R., Croteau, P. L., Onasch, T. B., Sueper, D., Worsnop, D. R., Zhang, Q., Sun, Y. L. and Jayne, J. T.: An Aerosol Chemical Speciation Monitor (ACSM) for routine monitoring of the composition and mass concentrations of ambient aerosol, Aerosol Sci. Technol., 45(7), 780-794, doi:10.1080/02786826.2011.560211, 2011a.

5. Ng, N. L., Canagaratna, M. R., Jimenez, J. L., Zhang, Q., Ulbrich, I. M. and Worsnop, D. R.: Real-time methods for estimating organic component mass concentrations from aerosol mass spectrometer data, Environ. Sci. Technol., 45(3), 910-916, doi:10.1021/es102951k, 2011b.

6. Reyes-Villegas, E., Bannan, T., Le Breton, M., Mehra, A., Priestley, M., Percival, C., Coe, H. and Allan, J. D.: Online Chemical Characterization of Food-Cooking Organic Aerosols: Implications for Source Apportionment, Environ. Sci. Technol., 52(9), 5308-5318, doi:10.1021/acs.est.7b06278, 2018. 